\title{
El envés de la historia. \\ Memoria, exilio, holocausto ${ }^{1}$
}

\author{
(The Hidden Side of History. \\ Memory, exile, holocaust)
}

Jorge Novella SuAREZ

Recibido: 18 de marzo de 2013

Aceptado: 26 de enero de 2014

\section{Resumen}

La memoria humillada necesita un rescate político y epistemológico, no puede ser sustraída en tanto que reflexión crítica del mundo en que vivimos. La racionalidad moderna se ha construido de muchas formas y hay que conocer sus patologías, únicamente así podremos afrontar sus efectos. No hay otro modo de construir nuestro futuro y vivir nuestro presente que incorporar y rescatar todas esas tradiciones con sus luces y sombras - para que podamos convivir sin odio.

Palabras clave: Historia, memoria, olvido, razón anamnética, exilio, Holocausto, justicia, verdad, testigo, escritura, muerte, dignidad, Ricoeur, Benjamín, Levi, Semprún, Améry, Steinberg.

\begin{abstract}
The humiliated memory needs a political and epistemologycal rescue; it cannot be eliminated as part of the critic reflection of the world where we live. Modern rationality has been built in many ways and one must know their pathologies, only in that way we will be able to confront its effects. There is no other way of building our future and live our present than to incorporate and rescue all those traditions -with their pros and cons- so that we can live without hate.

\footnotetext{
1 Este trabajo se enmarca en el proyecto de investigación "El pensamiento del exilio español de 1939 y la construcción de una racionalidad política” (FFI2012-30822), financiado por el Ministerio de Economía y Competitividad.
} 
Keywords: History, memory, oblivion, associative anamnesis, exile, Holocaust, justice, truth, witness, dignity, Ricoeur, Benjamin, Levi, Semprún, Améry, Steinberg.

\section{Historia y memoria}

El narrar, el escribir es uno de los modos más antiguos para entender la experiencia que es nuestra vida. Lo que somos, aquello que fuimos o que nos gustaría ser y hacer. Nuestras vivencias conforman nuestra identidad y es así como nos relacionamos con los demás, siendo el modo de objetivarlo, la escritura. También es memoria, sin ella no seríamos nada. Eso sí, hay que adjetivar, la memoria de nuestros protagonistas es una memoria ejercida, no impedida, obligada o manipulada, como era común en la España del nacionalcatolicismo franquista.

Surge así ante nosotros el ineludible compromiso de reflexionar acerca de la relación de la Historia con los distintos modos de memoria, así como los diferentes tipos de olvido (voluntarios, reprimidos, impuestos, etc.) que están presentes y activos en cualquier modo de aproximarse a estas cuestiones. Paul Ricoeur lo ha hecho modélicamente con su fenomenología de la memoria, una descripción exhaustiva de los vericuetos de la evocación; aborda el cómo representarnos los hechos que acontecieron, actualizando algo pasado y, por tanto, ausente de nuestro presente. La memoria es siempre algo actual y que se constituye - ya lo señaló Locke - en criterio de identidad. Ser quien soy tiene una relación directa con la conciencia de lo que he sido, es un proceso de constitución progresiva y permanente de coincidencia de la memoria.

En la actualidad, asistimos a un acoso de la memoria histórica, a una manipulación de la memoria que siempre "provienen de la ideología"2 que quiere imponer un determinado relato, una historia oficial, una tradición que ahogue a las otras. Esa imposición no es otra cosa que un modo de dominación que a unos seduce, a otros tranquiliza, también intimida y muchos nos rebelamos porque se quiere excluir de la Historia aquello que fue una parte sustancial de la misma. Es algo que viene de lejos, pues el pasado, demasiadas veces, resulta inoportuno. Es el silencio de la memoria ${ }^{3}$, donde la exclusión es la nota dominante, pues

El control de la memoria no es solo propio de los regímenes totalitarios; es patrimonio de todos los celosos de la gloria. ${ }^{4}$

\footnotetext{
2 Ricoeur (2003), p. 112.

3 Novella (2008), pp. 429-473.

${ }^{4}$ Ricoeur (2003), p. 117.
} 
De este modo la historia se desliza como una narración impecable que entronca y surge de una tradición inventada que se postula como única y que pasa por ser eso que se denomina "historia oficial". Es la que se conmemora y glorifica, aquella que se enseña para reescribir y no contar todo lo que ocurrió; Ricoeur la caracteriza como "un pacto temible entre rememorización, memorización y conmemoración." 5 La memoria obligada. La memoria histórica y colectiva que recoge todas las tradiciones - sin excluir ninguna, sea cual fuere - es el esfuerzo a realizar. Memoria de vencedores y vencidos, donde las víctimas y los supervivientes son los protagonistas del relato; paradójicamente los verdugos o responsables no han comparecido nunca ante un tribunal y, lo que es más deleznable, no han pedido perdón, para eso han escrito la historia.

Es así que la memoria se convierte en "matriz de la historia". Pues la relación entre memoria y verdad es siempre necesaria, al igual que en el caso de las víctimas-verdugos tiene una relación estrecha con la justicia como equidad. Ya que sólo a través de ella las víctimas, los exiliados, son reconocidos como existentes, constatando que su vida no ha sido una patraña o una farsa, más bien han sido el eslabón preciso para enlazar con las generaciones jóvenes (basta recordar a Améry o a Zambrano). Únicamente así salen de ese ostracismo, de esa alienación que les ha hecho ser extraños frente a lo que era un elemento clave en su identidad. Frente a una memoria del mal que en aras de lograr la "paz social" deja en las tinieblas a los que fueron protagonistas de parte de la historia.

Nada se olvida, la memoria es siempre algo vivo que se lleva siempre a cuestas $\mathrm{y}$ con lo que uno se reconoce; identidad y autoconocimiento dependen de ella. Por todo esto, Ricoeur afirma que "el historiador ha de ser el médico de la memoria". No se trata de una historia como disciplina, algo que haya que explicar y enseñar, y donde establecemos periodos, transiciones, esquemas cíclicos, generaciones, efemérides, etc. No se trata de eso. Es una memoria que tiene un objetivo: no olvidar. Su lema podía ser: Contra el olvido, ¡recuerda siempre! Ese es el deber de la memoria frente a una programación que pivota en la indiferencia y que pretende borrar las huellas, así como el significado y legado de las víctimas y testigos. Como si nunca hubieran existido, negando su personalización. Es así que nace la misión del superviviente: contar lo que pasó, no olvidar, vivir para referir lo que sucedió. Es el tiempo del testigo.

La razón anamnética, la rememorización es esa reminiscencia que consiste en la acción mediante la cual representamos y ofrecemos a la memoria el recuerdo de una cosa que pasó; que a su vez, como indica Homero en La Odisea y Sófocles en Edipo Rey, es anagnorisis, esto es, reconocimiento de algo oculto y desconocido hasta ese momento, como constatación de que lo que se narra existió, "reconocer un recuerdo es reencontrarlo" nos explica Ricoeur6.

\footnotetext{
5 Ricoeur (2003), p. 117.

6 Ricoeur (2003), p. 564.
} 
La toma de conciencia de un hecho traumático es el punto de partida, puede que hayan actuado los mecanismos inconscientes de represión, pero el actualizar, el traer al presente esas experiencias son - más allá del psicoanálisis - la tarea del testigo y del superviviente. Ellos han sido protagonistas y espectadores del terror y de la destrucción del hombre por el hombre. No ya en una guerra. Es peor. Han sido exiliados, perseguidos, torturados ("convertidos en carne" como expresivamente recalca Améry) y ahora les quieren negar que eso aconteciera. De ahí que es menester la resistencia frente a la negación de lo que han sido sus vidas: Kertestz, Levy, Steinberg, Semprún, Améry, Grossman, Déry y tantos otros. El énfasis y el estilo es diferente en cada uno de ellos pero su imperativo humanitario es narrar al mundo lo que pasó, lo que vieron, lo que sucedió según ellos, precisamente para que nunca más vuelva a ocurrir, siendo la escritura una afirmación de la vida.

Siempre ha existido una organización del olvido, el enfrentamiento entre la memoria de los vencedores y la de los vencidos que ha diferenciado Benjamin. Hoy, casi ocho décadas después de la guerra civil, hay fuerzas políticas que hacen una exhortación a olvidar la barbarie de la guerra civil en pro de la concordia y de una España del futuro. Muchos son herederos de los vencedores de aquella guerra incivil, de ahí que nombres de padres, tíos, abuelos, etc., están en lápidas de iglesias o en cruces de caídos ¿y las otras víctimas? Están en cunetas y fosas sin reconocimiento para sus familiares que quieren darle una sepultura digna. Esta es la cuestión. El problema es que todavía encontramos personas jóvenes - que no vivieron aquellos años - en los que persiste la semilla del odio. Y los descendientes de los vencidos, que como Electra, no olvidan las ofensas. No es difícil colegir la relación entre amnistía y amnesia, la primera (de amnestia) es el olvido de los delitos políticos otorgado por la ley ordinariamente a cuantos reos tengan responsabilidades análogas entre sí; la segunda (de amnesia) es la pérdida o debilidad notable de la memoria, el olvido. Ricoeur resalta esta relación, siendo así como el pasado desaparece de la problemática presente; pues la amnistía es:

un olvido jurídico limitado, pero de amplio alcance, en la medida en que la suspensión de los procesos equivale a borrar la memoria en su expresión testificativa y a decir que nada pasó. ${ }^{7}$

Es una reapropiación del pasado, donde el perdón es mera retórica (pues significa sumisión) y donde la vida cotidiana se fundamenta en un acto violento como es la guerra, una sociedad no puede estar basada en una dialéctica amigo-enemigo. Es una asimetría permanente, de ahí que siempre exista esa posición-imposición dominante, sustanciada en el predominio de esa tradición glorificada y conmemorativa que una y otra vez no recoge otros acontecimientos y que deja a un lado la lógica

\footnotetext{
${ }^{7}$ Ricoeur (2003), p. 590.
} 
del disenso. Es un discurso tamizado, pero desde la perspectiva de los victoriosos. Es aquí donde muchos autores (la mayoría de religión judía) plantean la cuestión del perdón con prioridad respecto de la verdad y de la justicia; necesitan convertir a la historia en una escatología y soteriología más que en un espacio donde la verdad y la justicia sean los sustentos de una paz cívica. El propio Ricoeur, al final de su libro, lo hace patente:

Si el futuro pudiese salvar del olvido la historia de los vencidos recordándolos, así coincidirían revolución y redención. ${ }^{8}$

Entre la salvación y la redención pensamos que la reconciliación cívica y la necesidad de hacer justicia es algo prioritario; es así como se desliga la dignidad de las víctimas, monopolizadas por el exclusivismo judío, ellas son los sujetos, independientemente de la religión que profesen o la etnia y nacionalidad a que pertenezcan. No es un castigo o sacrificio, ni prueba para la salvación. Muchos judíos asimilados como Améry o Steimberg han coincidido en esta cuestión. Pero ¿y los otros? Gitanos, los que procedían del Este y que eran esclavos para los nazis, los republicanos españoles (Rotspanier) ${ }^{9} \mathrm{y}$ otras nacionalidades. A ellos hay que vindicarlos y rehabilitarlos por ser también víctimas, la mayoría de las veces invisibles y opacos por entender el exterminio únicamente como Shoah 10 e instrumentalizarla para diversos fines. La voz "Holocausto" 11 en el DRAE tiene tres acepciones: 1. Entre los israelitas especialmente, sacrificio en que se quemaba toda la víctima. 2 Gran matanza de seres humanos. 3 Acto de abnegación total que se lleva a cabo por amor. Evidentemente lo utilizo en su segundo significado, los españoles que murieron en Matthausen o Gusen no lo hicieron como una inmolación de carácter religioso. No. Murieron por haber sido republicanos y defender sus ideas.

Es así como entiendo que esta ecuación entre Historia y Memoria debe tener como resultado la Verdad y la Justicia. Sé que es harto difícil; prácticamente imposible. Pero el deber de la memoria, como insiste Ricoeur, "es el deber de hacer jus-

\footnotetext{
8 Ricoeur (2003), p. 650.

9 Serrano Suñer, cuñado de Franco y Ministro de Exteriores dijo a las autoridades nazis: "Hagan lo que quieran con ellos. Esos no son españoles.”

10 Para lo que ha supuesto la Shoah desde la fundamentación del Estado de Israel y sus efectos, Traverso (2007): pp. 69-75 y Zertal (2010).

11 "nunca me ha gustado la palabra "Holocausto... no me parece un término apropiado, es retórico y, sobre todo, erróneo. Representó un punto de no retorno en términos de proporciones, sobre todo de recursos, porque por primera vez en tiempos recientes el antisemitismo se convirtió en un proyecto planificado, organizado a nivel de Estado, no por influjo de un consenso tácito, como había ocurrido en la Rusia de los zares; esto, en cambio, era un acto de voluntad. No había escapatoria posible, toda Europa se convirtió en una enorme trampa, esto fue lo novedoso y lo que determinó para los judíos un profundo cambio, no solamente en Europa sino también para la comunidad judía en Estados Unidos y para los judíos del mundo entero", en Levi (2005).
} 
ticia"; sólo así no se verá fracturada la historia viva, esa memoria vivida, pura vivencia que es "matriz de la historia."12 La negación del pasado es la negación del otro, de ese prójimo que somos y en el que nos reconocemos como seres humanos, al margen de religiones, etnias, ideologías o nacionalidades.

\section{El trapero de la historia}

Benjamin no llegó a conocer los horrores de los campos de exterminio, pero sí el exilio y la deportación, se adelantó a su tiempo y tuvo el triste privilegio de ser un pionero de los llamados "avisadores del fuego". Se suicidó en Port Bou, septiembre de 1940, al pensar que la policía franquista lo iba a entregar a la Gestapo, pero su calvario se había iniciado con los estragos del exilio en 1933 tras la victoria del nacionalsocialismo. De ahí que su testimonio y reflexión sobre la memoria y la historia, esencialmente sus Tesis de Filosofia de la Historia ${ }^{13}$ son lúcidas e ineludibles para transitar y comprender los efectos de la Guerra Civil Española y la Segunda Guerra mundial sobre el individuo, teniendo en cuenta que

Una generación que todavía había ido a la escuela en tranvía tirado por caballos, se encontró súbitamente a la intemperie, en un paisaje en que nada había quedado incambiado a excepción de las nubes. Entre ellas, rodeado por un campo de fuerza de corrientes devastadoras y explosiones, se encontraba el minúsculo y quebradizo cuerpo humano. 14

Los problemas se inician cuando lo excepcional se convierte en cotidiano, en lo que rige el día a día, así deviene la dictadura; sea en la República de Weimar o en el golpe de Estado del 18 de julio. Emerge sobre la derrota el pasado de los vencedores, "el único que tiene futuro", hasta el punto que

tampoco los muertos estarán seguros ante el enemigo cuando este venza. Y este enemigo no ha cesado de vencer. 15

Nos descubre el filósofo alemán un nuevo modo de mirar la historia y la vida, es la perspectiva del Ángel de Klee que no presagia nada bueno. El Angelus Novus vuela hacia delante pero tiene el rostro vuelto hacia el pasado, lo que contempla le produce espanto: sólo tiene ante sí los escombros, las ruinas que es el territorio en el que se desenvuelve el trapero de la historia, todo lo destruido, arrojado a las cunetas de la vida es donde fija la vista nuestro hombre. Como en el cuadro de Klee

\footnotetext{
12 Ricoeur (2003), p. 119.

13 Benjamin (1990), pp. 175-191.

14 Benjamin (1991), p. 112.

15 Benjamin (1990), p. 181.
} 
Ha vuelto el rostro hacia el pasado. Donde a nosotros se nos manifiesta una cadena de datos, él ve una catástrofe única que amontona incansablemente ruina sobre ruina, arrojándolas a sus pies. 16

El sujeto de Benjamin es la víctima, el desplazado, "el que sufre y se rebela", prefigura y proyecta en el tiempo los efectos de la llamada "solución final" y no porque el mal sea algo banal, sino porque el mal radical está presente en los hombres de esa Kultur que Europa ha tenido por modelo. Es el huracán "que nosotros llamamos progreso" y que conduce a la catástrofe. Reyes Mate, en su ineludible comentario al texto de Benjamin, apuesta por esa narración anamnética, por esa recordación que tiene como objeto rescatar del pasado "el derecho a la justicia". Agrega que es preciso

reconocer en el pasado de los vencidos una injusticia todavía vigente, es decir, leer los proyectos frustrados de los que está sembrada la historia no como costos del progreso sino como injusticias pendientes. 17

Las víctimas de la historia son aquellos que "no han podido argumentar", tienen que reivindicar que "la memoria es una categoría política, pública y no sólo privada; además, la memoria no produce sólo sentimientos sino también conocimiento."18 En el recuerdo hay transmisión de conocimiento, aparte de la carga ética como exigencia de reparar lo que el olvido, la amnesia, e incluso, la amnistía (como en el caso de la Transición española) dejó al borde del camino. La razón es que "No es posible construir el presente, ni el futuro sin la memoria”. Vencidos y víctimas deben tener su voz en la Historia.

Recordar simboliza el incorporar a las conciencias de las gentes lo despojado, único modo/método de combatir la barbarie. Palabras vacías cuando los gritos del silencio de testigos que recuerdan las víctimas tienen que abrirse camino entre la indiferencia y el negacionismo. Y aquí Benjamin es capaz de captar "lo que hay de vida en lo dado por finiquitado", recupera entre las ruinas al hombre y a la mujer que han sido excluidos, pues donde existe destrucción y escombros está la mirada de Benjamin para rescatar y salvar del pasado e intentar desplazar a la política como visión e interpretación hegemónica de la historia. Sin ninguna escatología o religión mediadora para alcanzar la verdad y la justicia. Aunque sea la del pueblo elegido, antes que la redención y la salvación son necesarias la Memoria y la Justicia. Eingedenken, la memoria de los vencidos, de los parias, de los que no tienen nada y se les niega hasta el relato de sus vidas. Memoria como "ejercicio de justicia", de

\footnotetext{
16 Benjamin (1990), p. 183.

17 Mate (2006), p. 25.

18 Arenas (2008).
} 
traer a la luz aquello que ha permanecido en el ostracismo porque convenía - en lógica del vencedor - negar la existencia, identidad y vida del otro, del prójimo. En la literatura de los campos de concentración - veremos - como aparece ese imperativo de recordar y contar lo que aconteció para que nunca vuelva a repetirse.

En sus últimos libros, La herencia del olvido y Tratado de la injusticia ${ }^{19}$, vuelve sobre las víctimas del terror y del terrorismo que durante demasiado tiempo fueron invisibles e insignificantes, advirtiendo que en Occidente durante siglos, "el prestigio lo ha tenido la violencia, no la paz." Repasa los ajustes y polémicas debidos a la memoria política, como denomina a la histórica.

\section{Los avisadores del fuego}

Benjamin es consciente del momento histórico que le toca vivir, del peligro y de la catástrofe que se cierne sobre Europa, por ello es un avisador del fuego. Alerta sobre lo que no llegó a conocer, pero vislumbró con una lucidez que ni el más pesimista de los agoreros podía pensar. El autor de El libro de los Pasajes

Supo leer en su tiempo el destino catastrófico al que se encaminaba Europa. No era un visionario, era un anunciador del fuego que supo leer su tiempo y descifrar claves ocultas, gracias a sus investigaciones sobre la memoria. ${ }^{20}$

Reconstruir, revisar no solo el genocidio realizado por los nazis, así como los efectos para su época; no es una tarea ajena a lo que pasó con los españoles que sufrieron la guerra civil, forzosamente se exiliaron, combatieron con las fuerzas francesas libres y colaboraron con los aliados a vencer a Hitler. Pero no a Franco. ¡Que paradoja más amarga! Por ellos y por los que perecieron en Mauthausen, Auschwitz o Buchenwald estoy escribiendo este artículo. Reivindicar una política de la memoria que reconozca lo que hicieron muchos hombres y mujeres españoles, junto a otros europeos o eslavos, sin importar la procedencia, por la dignidad de la humanidad. La historia escindida, la destrucción de la vieja Europa y el desgarramiento de sus habitantes, la lucha contra la barbarie del nazismo. Nosotros hemos disfrutado de una Europa próspera gracias a aquellos que dieron sus vidas, todavía hoy, cuando tenemos la distancia que da el paso de setenta y cuatro años de la guerra civil y sesenta y ocho de la segunda contienda internacional, las heridas siguen sin cerrar aunque se hablara de reconciliación, ¿la ha habido de verdad? Queda pendiente el reconocimiento de una parte de las víctimas, auténticos muertos sin sepultura, para cerrar definitivamente este episodio que pone en primer plano las caren-

19 Mate (2008 y 2011).

20 Arenas (2008). 
cias de todo proceso de transición a la democracia. Los efectos de la catástrofe, así como su auténtica dimensión, los encontramos en las ruinas, en los escombros, pues ellos son muestra de nuestra caducidad y decadencia. Pero, como ya he indicado, son testimonio de esa existencia pretérita que ahora se pretende anegar en las conciencias. Ya que es el testimonio físico de la razón de los vencidos que resisten frente al desahucio de la memoria, sobre ellos se cierne el silencio de exiliados y víctimas, pues hablando de Auschwitz, Reyes Mate, parafraseando a Primo Levi, afirma que lo importante era que

no debía quedar ni rastro para no dar pie a la memoria. Lo que, sin embargo, hace la memoria es fijarse en la historia posterior a la catástrofe, llamando la atención sobre cómo esta se construye sin rastro de los desaparecidos. ${ }^{21}$

El testigo siempre trae el peligro de hacer ver las cosas de otro modo, es otra versión no oficial, que tampoco se conmemora... pero está ahí. El hombre que ha sufrido cualquiera de estas penalidades no tiene que ser un héroe, cada uno ha sucumbido o resistido como ha podido. Tampoco es un hombre pasivo, abandonado a su suerte, no; a través del recuerdo actualiza el peligro y el sufrimiento rescatándolo en lo que Benjamin llama "días de recordación." Esa razón anamnética es también una razón práctica porque la dimensión moral es ineludible, ya que Auschwitz

no es sólo el campo del tormento, sino sobre todo el lugar de la injusticia del sufrimiento inflingida al pueblo judío y, a través de él, a la humanidad del hombre. 22

Esta experiencia vivida da lugar a otro relato "que se transmite de boca en boca es la fuente de la que se han servido todos los narradores" 23 , hay una serie de consideraciones que confluyen con la memoria, el recuerdo y la experiencia vivida, de tal suerte que:

el narrador toma lo que narra de la experiencia; la suya propia o la transmitida. Y la torna a su vez en experiencia de aquellos que escuchan su historia. ${ }^{24}$

Para que el narrador-testigo pueda retener los hechos y poder rememorarlos, teniendo en cuenta que

\footnotetext{
${ }^{21}$ Mate (1991), pp. 118-119.

22 Mate, (2003), p. 151. Podemos incluir gitanos, húngaros, polacos, etc. La humanidad trasciende al pueblo judío.

23 Benjamin (1991), p. 112.

24 Benjamin (1991), p. 115; véase el apartado XIII, pp. 124-125, sobre memoria, rememoración y recuerdo.
} 
No solo el saber y la sabiduría del hombre adquieren una forma transmisible, sino sobre todo su vida vivida, y ése es el material del que nacen las historias... sin percatarse de ello, se encuentra a sí mismo, así aflora de una vez en sus expresiones y miradas lo inolvidable, comunicando a todo lo que le concierne, esa autoridad que hasta un pobre diablo posee sobre los vivos que lo rodean. En el origen de lo narrado está esa autoridad. ${ }^{25}$

Se establece así una complicidad entre el narrador y lo que cuenta su relato, se produce una empatía, Benjamin utiliza el final de La educación sentimental de Flaubert para ejemplificarlo. Lo bello y el espanto subsistirán en todos nosotros por los efectos de la rememoración y gracias al narrador:

Su talento es de poder narrar su vida y su dignidad; la totalidad de su vida... El narrador es la figura en la que el justo se encuentra consigo mismo. ${ }^{26}$

Hurbinek, el niño de tres años que había nacido en Auschwitz y que murió en los primeros días de 1945, "libre pero no redimido. Nada queda de él: el testimonio de su existencia son estas palabras mías." 27 Gracias a él, a su testimonio, pervive entre nosotros, cada uno de sus lectores hacemos que Hurbinek no sea algo etéreo e invisible sino una víctima más del genocidio.

\section{Exilio, forma de vida}

El exilio es algo que comparte España 28 con los países invadidos por los nazis y, la Alemania de los años treinta, pero ya es tarde, demasiado tarde. La causa es la misma y los efectos son idénticos, se produce un destierro político, cultural y moral. El exilio además es pérdida y resistencia, teniendo en cuenta que las señas de identidad del exiliado está, precisamente, en esa errancia. El exiliado es un hombre devorado por la historia. Es el hombre exánime, aniquilado, desfallecido, patitieso, perdido, vencido sin remisión, muerto en vida, sin vigor ni palpitar para arrostrar todo lo que tiene ante sí. Ruina de aquél que fue, sin acmé ni floruit, es más que nunca exsul umbra, una sombra prohibida. Si el holocausto es la memoria de la violencia, el exilio es la memoria del olvido. Son los avisadores del fuego y, a la vez, aquellos que son traperos de la historia, de ahí que María Zambrano se yergue para reivindicar el exilio como forma de vida, y a los exiliados con ella, identificándolos con la desolación y la destrucción que representan:

\footnotetext{
25 Benjamin (1991), p. 121.

26 Benjamin (1991), p. 134.

27 Levi (1997), p. 23.

28 Novella Suárez (2008) y (2012) sobre el exilio español de 1939 (exterior e interior), así como la condición del exiliado.
} 
Las ruinas son lo más viviente de la historia, pues sólo vive históricamente lo que ha sobrevivido a su destrucción, lo que ha quedado en ruinas. ${ }^{29}$

Como la Numancia celtíbera arrasada por Escipión el Africano, esta otra Numancia errante, la España peregrina, resiste entre escombros y despojos de ella misma, pues ya no pueden causarle más dolor e infligirle más destrucción. Las sombras prohibidas pero no destruidas están ahí, nadie puede vencer a la voz dormida de la memoria. El exilio se convierte en condición, esto es, un estado en que se halla una persona, que en este caso se convierte en algo permanente; es una cicatriz que no se cierra. Améry lo refiere como una "voluntad del sentimiento de catástrofe que domina toda mi existencia", además uno no se puede sustraer a ello, pues es su identidad ese desarraigo ${ }^{30}$. Son apátridas, fracasados y marginales, pero ellos son los que

Durante la guerra, los exiliados son los únicos que aprehenden Auschwitz porque son los únicos que pueden identificarse con las víctimas del genocidio y estar en condiciones de pensar ese desgarro de la historia (los supervivientes necesitarán tiempo para poner en perspectiva e intentar explicar su experiencia). Su estatuto de parias agudiza, pues, la mirada crítica de los intelectuales exiliados. ${ }^{31}$

Tengamos en cuenta que los supervivientes de los campos regresaban a sus países respectivos, en cambio para los exiliados españoles - muchos de ellos entraron con el General Leclerc en la liberación de Paris - era imposible retornar a España. En Alemania resultaban muy molestos y a partir de la amnistía de 1948 muchos nazis volvieron, en un país destruido verdugos y víctimas, pero éstas eran más molestas, pues los verdugos vivían todavía, era la presencia de ese mal radical que como exigía Thomas Mann les llevara al "horror, la vergüenza y el arrepentimiento". Los exiliados españoles tengan que vivir una larga noche de piedra, una escalera de horas lentas, donde a veces resultan incómodos, aun siendo pieza clave en su ejemplo de lucha contra el régimen de Franco. La amnistía conllevó la amnesia, por eso reivindico memoria de la memoria y memoria de los vencidos.

\section{Pensar Auschwitz}

Nombrar, invocar Auschwitz nos lleva a identificar lo peor de este siglo XX, siglo de horrores, guerras y exterminios. Y seguimos sin aprender la lección, Améry

\footnotetext{
29 Zambrano (1973), p. 250-51.

30 Jean Amery publica en 1935 un fragmento de su novela Los náufragos, con título premonitorio, "Los desarraigados" (Die Entwurzelten), en el Die Brücke de Hermann Hakel.

31 Traverso (2001), p. 49.
} 
subraya que es "el pasado, presente y futuro de la Humanidad" y Adorno nos alertó que suponía "la ruptura de la civilización". Por eso, hoy, más que nunca es menester pensar Auschwitz. Conocemos sus efectos en estos tiempos donde vemos que hombres y mujeres no se han vacunado del odio al otro, priman las políticas del olvido, vacunadas con mala conciencia pues todo es pasado y sobre éste qué mejor que el silencio; Kershaw, autor de la mejor biografía de Hitler ofrece un testimonio que no necesita comentarios: "La carretera a Auschwitz la construyó el odio, pero la pavimentó la indiferencia." El "no me atañe, algo habrá hecho, cerrar la puerta aunque se tuvieran que tapar los oídos". Esta cuestión va enlazada con la responsabilidad y culpabilidad del pueblo alemán que luego abordaría Karl Jaspers en sus conferencias, en la Universidad de Heidelberg, de enero y febrero del semestre de invierno, curso 1945-1946 sobre Die Schuldfrage.

Cavilar sobre Auschwitz es una tarea ingrata, dura, pero que cualquier persona no debe eludir y, mucho menos, contentarse con que fue producto "del irracionalismo"; debe adentrarse hasta el corazón de las tinieblas, para ver la encarnación de ese coronel Kurtz planetario, del mal absoluto o radical, pero nunca banal. La reflexión conduce a que aflore lo peor que tenemos cada uno de nosotros, pues las esferas de lo humano son sustituidas por aquellas que se dedican a reducir al hombre a carne, sometido al sufrimiento. Benjamin no conoció estos campos de exterminio pero sí supo proyectar las cuestiones que en torno al testimonio debe afrontar el narrador, le había impactado el enmudecimiento de aquellos que volvían del campo de batalla en la guerra del 14, eran los efectos de ese "trastorno social y psicológicamente profundo" que funda el siglo XX, donde el narrador tiene que

Articular históricamente lo pasado... significa... adueñarse de un recuerdo tal y como este relampaguea en un instante de peligro (...) tampoco los muertos estarán seguros ante el enemigo cuando éste venza. Y este enemigo no ha cesado de vencer. 32

Así nace este siglo del horror y de la barbarie, de Auschwitz al Gulag, pasando por Hiroshima, Vietnam, Camboya, los Balcanes, Ruanda, Uganda, Congo, Cono Sur... todo un elenco de crímenes contra la humanidad en el siglo que el hombre pisó la luna. Pocos se acuerdan que en la Gran Guerra, ochocientos mil armenios fueron asesinados por el Imperio Otomano. Todos nosotros somos testigos de nuestro tiempo y aquellos que sobrevivieron tienen un valor especial

El testigo bien podría ser, en nuestro tiempo, quien viniera a ocupar el lugar de la resistencia, el de la oposición al olvido, es decir, el espacio del narrador que tanto anhelaba Benjamin y que parece haber sucumbido en la Gran Guerra. 33

\footnotetext{
32 Benjamin (1990), p. 180-181, (1990), pp. 112 y ss. "El narrador es la figura en la que el justo se encuentra consigo mismo."

33 Cohen (2006), p. 58-59.
} 
Testigo que guarda, a través de la escritura, la descripción minuciosa del día a día, como hacen Levi o Solzhenitsyn. Para esta literatura el proceso de Eichmann, en 1961, es desencadenante, en pocos años aparecen los primeros testimonios ${ }^{34}$ que habían estado corroyendo la memoria de los supervivientes. El significado que encierran es necesario para una vuelta a la normalidad en una Europa que asiste al llamado "milagro alemán" y que va a toparse de bruces con el pasado reciente. Un pasado inoportuno e inconveniente que recordaba cosas nimias como la sustitución del nombre por el número, la tecnificación de la barbarie y del odio como instrumentos de destrucción de la persona. No pudieron matarlos a todos, la frase de los SS en los campos: "Ninguno quedará para contarlo" y "Aquí no hay porqué" que día tras día, cuenta en Los hundidos y los salvados, es donde se afirmaban los presos de los campos; el resistir a que fueran los verdugos quienes escribieran la historia del Lager. Las víctimas, los hundidos, muertos, los llamados Muselmänner ${ }^{35}$ viven en el recuerdo y memoria de aquellos que nos cuentan la otra historia, la que está en las cunetas o hibernada. Lo anticipa Levi:

Nos quitarán hasta el nombre: y si queremos conservarlo, deberemos encontrar en nosotros la fuerza de obrar de tal manera que detrás del nombre, algo nuestro, algo de lo que hemos sido permanezca. 36

El caso de Hurbineck, citado anteriormente, lo conocemos hoy por la narración del autor italiano. Ese niño vive cada vez que recordamos su existencia pues el objetivo del nazismo era transmitir que nunca hubiera existido, la finalidad no era otra que "erradicar el concepto de ser humano", como apunta H. Arendt. Así comprobamos que la escritura tiene ese poder de hacer presente la vida, el narrador es aquí fedatario de los hundidos y Hurbineck es todos los niños que murieron de hambre o en la cámara de gas.

Hay que contar lo que sucedió, la escritura, la lengua se convierte en un elemento de la verdad y la justicia, "hay que narrar ante el enmudecimiento de la lengua" 37 , pues de ésta también se apropiaron y mutaron los nazis, en un intento más de expropiar y apropiarse el modo de describir la realidad. Klemperer en su famoso texto

\footnotetext{
34 Levi (1956), Semprún (1963).

35 Muselmann (pl. Muselmänner) término alemán despectivo, literalmente, "musulmán"; utilizado ampliamente entre los prisioneros de los campos de concentración para referirse a presos que se encontraban cerca de la muerte por agotamiento, inanición o desesperanza, se originó a partir de la similitud entre el borde de la muerte y la imagen de un musulmán postrándose en el suelo en la oración. Viktor Frankl, El hombre en la encrucijada, (1979) escribe:” ¿Sabéis a quién llamamos aquí un "musulmán"? Al que tiene un aspecto miserable, por dentro y por fuera, enfermo y demacrado y es incapaz de realizar trabajos duros por más tiempo: ése es un $<$ musulmán>. Más pronto o más tarde, por regla general más pronto, el "musulmán" acaba en la cámara de gas."

36 Levi (1997), p. 42.

37 Cohen (2006), pp. 55-70.
} 
LTI. La lengua del Tercer Reich. Apuntes de un filólogo 38 estudia el proceso de cosificación - parejo al del ser humano - que se produce en la lengua alemana, ya que "por ciertas palabras" uno podía ir a la cárcel, sometido a tortura, etc. Si esas palabras eran pronunciadas en contra de quien ostentaba el poder político, léase Hitler (como es el caso), Stalin, Franco, Videla o Pinochet.

\section{Escritura, memoria de la muerte}

"Hay tantos recorridos de la memoria como itinerarios vitales" indica Enzo Traverso. Si encontramos constantes en muchos escritos, que coinciden con muchos del exilio español: la Gran Guerra no acabó con la Paz de Versalles, el ascenso de los fascismos y la explosión del comunismo, los intentos de sobrevivir en este tiempo de la democracia liberal y el parlamentarismo, todos los ismos vencen, se han acabado para siempre las falsas promesas de felicidad basadas en el progreso... es la constatación de la catástrofe, y lo que hay que hacer, subraya Benjamin, es "organizar el pesimismo". El nido de la serpiente estaba en los últimos años de la Guerra del 14 y el nuevo hombre es Hitler, a quien Traverso caracteriza como un individuo de:

esperanzas apocalípticas, de impulsos vitalistas e irracionales, como el triunfo simultáneo de la naturaleza y la técnica, de la fuerza y el mito, elementos que les seducen ante el cataclismo de la guerra y el hundimiento del antiguo orden europeo. 39

Deliberar sobre Treblinka, Auschwitz o Mauthausen (donde murieron más de cinco mil españoles de los siete mil que llegaron), me lleva a pensar en ese exilio permanente, parecido al de Ovidio, invisibles, negados, "malos españoles", son la generación del toro 40 , en palabras de María Zambrano. Encontramos un espíritu de sacrificio cívico y político, alejado de cualquier connotación religiosa, por la causa de la II República y sus emblemas. Podemos entrelazar, tanto en España como en la Europa invadida, derroteros y direcciones vitales similares en las que prisioneros del mismo Lager, dan lugar a testimonios aparentemente similares pero muy distintos en el modo de afrontarlos, al igual que son diferentes sus vivencias. Esther Cohen se ha ocupado de lo que significa ese acto de contar, donde en la mayoría de las veces subyace la necesidad de comprender hechos que habían sido totalmente ajenos hasta ese momento. El narrar lo acontecido es parte de la cura, al objetivar el pasado se proyecta el futuro y se aprehende el presente, de ahí que las confesiones

\footnotetext{
38 Klemperer (2001).

39 Traverso (2001), p. 24.

40 Lo asocio a una generación joven que encarnó la II República y a los versos de Miguel Hernández: Como el toro he nacido/para el luto y el dolor/Como el toro me crezco/en el castigo.
} 
tardaron en salir a la luz para la mayoría de ellos, Levi escribe Si esto es un hombre en 1947, se publicará en 1956, La tregua en 1963 y Los hundidos y los salvados en 1986, un año antes de suicidarse. Acabada la contienda nadie quería saber nada de ellos ni de sus declaraciones, la indiferencia, el silencio y el ostracismo formaban parte del imaginario colectivo de su tiempo. Después de tanto sufrimiento la razón cínica exclamaría: ¡ahora vienen estos a remover heridas que están cerrándose!

Muchos judíos experimentaron culpa por haberse salvado, la eterna pregunta: ¿por qué él y no yo? Desde luego los jóvenes Kestestz (14 años), Semprún (18 años) o Steinberg (17) no sintieron en absoluto ese sentimiento de culpa o de mala conciencia. En tanto que jóvenes lucharon con denodado esfuerzo por la supervivencia, incluso a modo de juego como encontramos en Sin destino:

En mi interior identifiqué un ligero deseo que acepté con vergüenza - porque aun siendo absurdo, era muy persistente-, el deseo de seguir viviendo, por otro ratito más, en este campo de concentración tan hermoso. 41

La escritura y la muerte es el título provisional que Jorge Semprún puso a la obra que hoy conocemos como La escritura o la vida 42 , el suicidio de Levi, el 11 de abril de 1987, fue el motivo que le llevó a escribir este texto clave en torno a la memoria, dedicado al recuerdo del horror en tanto que homenaje a las víctimas y a los supervivientes, a lo que él llama: los efectos del mal absoluto. Cinco años más joven que Levi, comparte con él las condiciones mínimas para la supervivencia: un buen estado de salud, saber alemán, cierta curiosidad43 y suerte. "Mis ojos son un espejo de desolación", eso es lo que refleja el rostro de un Semprún de 22 años que recibe a los liberadores de Buchenwald, la vanguardia del III ejército del General Patton, en la primavera de 1945. Paisaje de espanto y pavor, rodeado de desolación pues

La muerte... nos concernía a todos era la sustancia de nuestras relaciones. No éramos otra cosa más que eso, nada más que esa muerte que crecía. 44

¿Esto se puede contar? La experiencia vivida "no es indecible", el superviviente, muchos años después, como testigo convierte su

testimonio en un espacio de creación. O de recreación. Únicamente el artificio de un relato dominado conseguirá transmitir parcialmente la verdad del testimonio. ${ }^{45}$

\footnotetext{
41 Kerstestz (2001).

42 Semprún (1998), (1 ${ }^{\mathrm{a}}$ 1995).

43 Entendida, habla Primo Levi, como el "deseo intenso de comprender", Semprún (1998), p. 320.

44 Semprún (1998), p. 30.

45 Semprún (1998), p. 25.
} 
La muerte y el mal están presentes a lo largo de toda la obra, tras la liberación, de vuelta a lo cotidiano, comprende que el Lager no es un hecho aislado, forma parte de la vida y ésta es la que genera el mal absoluto. Esta experiencia le ayudará al clandestino Federico Sánchez, en el Madrid de los años cincuenta, pues tras lo pasado "nada podía sucederme. Ya había pagado el precio". El joven Semprún nunca se abandonó, pues la mirada de odio de los SS "le remitía a la vida. Al deseo insensato de durar, de sobrevivir: de sobrevivirle. Al propósito firme de conseguirlo." Levi mantiene cómo el peligro sigue ahí, pues

Hay indicios que permiten pensar que quieren olvidar o algo peor: negar. Es muy significativo: quien niega Auschwitz es precisamente quien estaría dispuesto a volver a hacerlo. 46

El silencio de supervivencia es el tiempo de incubación que se ha necesitado para poder narrar las vivencias en los campos de exterminio. Muchos no pudieron hacerlo inmediatamente, ni siquiera hablar de ello, lo cual como catarsis era conveniente y necesario. En 1956 se publica Si esto es un hombre que marca el canon de los que consideraron que dar testimonio de lo vivido era una tarea moral para que sus semejantes supieran la verdad y, ya que justicia era difícil de obtener, al menos no olvidaran; sentía una necesidad física pues "las cosas que había vivido, padecido, me quemaban por dentro." El mismo año de su liberación intenta escribir, en Ascona en 1945, pero tras meses de esfuerzo abandona ese proyecto, pues

las dos cosas que pensé me atarían a la vida - la escritura, el placer - me alejaron por el contrario de ella, me remitieron sin cesar, día tras día, a la memoria de la muerte, me devolvieron a la asfixia de esta memoria. ${ }^{47}$

No podía volver a su patria, nunca fue de los que decían estar dispuestos a morir por su patria; por otras cosas si, la lucha por la libertad contra el nazismo. Pero la experiencia vivida está ahí, él propio Semprún indica como una noche

Hablé por primera y última vez, por lo menos en lo que a los dieciséis años siguientes se refiere. Por lo menos con tanta precisión en los detalles. Hablé hasta el alba, hasta que se me puso la voz ronca y se quebró, hasta quedarme sin voz. Conté la desesperanza a grandes rasgos, la muerte en todos sus recovecos.

\footnotetext{
46 Levi (2005).

47 Semprún (1998), p. 125. Semprún lee en 1963 La tregua, año de su aparición, que relata el trayecto inverso de El largo viaje (publicados ambos con un mes de separación), el regreso desde la liberación de Auschwitz por las tropas soviéticas hasta su llegada a Turin en octubre de 1945). Los hundidos y los salvados, el último volumen de su trilogía aparecerá en 1983, cuatro años antes de que Primo Levi se suicide en su casa de Turín a los 66 años. Destaca que 1963 es el año que aparece Un día en la vida de Ivan Denisovich de A. Alexander Solzhenitsyn.
} 
Han transcurrido dieciséis años desde aquella noche y ahora empieza a hablar en nombre de los amigos que habían muerto,

en nombre de su silencio, de todos los silencios: miles de gritos ahogados. Quizá porque los aparecidos tienen que hablar en el lugar de los desaparecidos, a veces, los salvados en el lugar de los hundidos. ${ }^{48}$

En el último capítulo de su novela encontramos las claves que se han ido entretejiendo, esa estancia en Buchenwald, es como el último bucle de Semprún: "Supe que volvía a casa", sus palabras brotan de "una memoria carnal y no de una reconstrucción teórica", así ha sido la experiencia del hombre que es "el recuerdo vivo, nauseabundo, del olor del horno crematorio." 49 La escritura ha colaborado a realizar esa labor de reconocimiento de sí mismo a través de los otros, la libertad y la fraternidad, la generosidad y camaradería de los hundidos, víctimas, salvados y supervivientes (como él) le han llevado de ser un aparecido a ser un bienaventurado. Había elegido la vida, atrás quedaba la escritura, pues "había escogido una prolongada cura de afasia, de amnesia deliberada, para sobrevivir" 50 , una y otra vez la memoria se atasca y detiene, por otro lado se acuerda perfectamente de hechos que sucedieron en el campo. Él mismo cuenta cómo sus intentos de escribir se sitúan antes o después de llegar a Buchenwald pero nunca arrancan en él, hay algo que lo impide: "Sólo el olvido podría salvarme."51

La memoria de la muerte implica el silencio de supervivencia, el regreso no puede tener una catarsis a través de la literatura o de la narración a otros, antes tendrán que pasar "años de glaciación parcial y partidista de mi pensamiento". Todo un proceso que han pasado los internos en los campos de exterminio, un largo desvanecimiento hasta que pasados muchos años, en este caso casi dieciséis, uno puede hablar, escribir de la muerte como elemento cotidiano. Y la necesidad de encontrar una lengua para expresarlo destacando cómo "La lengua de mi infancia fuera la de la libertad, no sólo la del exilio y del recuerdo angustiado, resultaba perturbador." La escritura o la muerte era una opción, algo que se experimentaba día a día, gentes que ya no querían vivir y que afrontaban su fin como el término del sufrimiento sin más, otros lo vivían como una inmolación, un sacrificio más frente a su dios para su salvación o redención. Muchos de los supervivientes de los campos de exterminio se suicidaron años después, la pregunta que surge inmediatamente es: ¿cómo es posible que estos hombres y mujeres que padecieron tanto, han puesto fin a su vida? La muerte voluntaria es saber que ya no le infringirán ni un ultraje ni una

\footnotetext{
48 Semprún (1998), p. 154.

49 Semprún (1998), p. 312.

50 Semprún (1998), p. 212.

51 Semprún (1998), p. 177.
} 
indignidad nunca más. Un triunfo final sobre los verdugos y el mal, así ellos administran su vida, saben que esa decisión final es suya y que nadie se la puede apropiar, incluso muchos de ellos lamentaban no haberse matado antes de sufrir los niveles de degradación que sufrieron en los campos.

Saber por qué se muere es importante, en esas circunstancias, resistir sabiendo por qué estaban allí y por qué podían morir. Es la entereza que tiene a la libertad como motor, unido al instinto de supervivencia que abandonaba a muchos, los llamados Muselmänner. Améry describe las torturas a que fue sometido, manteniendo que a los que habían padecido estos suplicios no se les podían exigir responsabilidades, aunque delataran a sus compañeros o inventaran falsos culpables pues el dolor es distinto en cada persona. No todos eran héroes, no todos fueron Jean Moulin. La muerte por agotamiento o "Sólo la muerte voluntaria podría distraerme y librarme de mi dolor", esa muerte "no sea más que una especie de vértigo, nada más." 52

La cartografía de la memoria histórica está en cada una de las obras de Semprún. No puede ser de otro modo, como he indicado, forma parte de su experiencia vivida, su existencia, al fin y al cabo. Sus novelas son cestos de cerezas donde siempre aparece la muerte con la peor de sus caras, la que el semejante lleva a cabo. Los verdugos son distintos, no prima lo humano, sino la etnia, la raza, la voluntad de exterminio, etc. Esa geografía del horror y del sufrimiento está en $E l$ largo viaje, Aquel domingo, Viviré con su nombre, morirá con el mío, La escritura o la vida, La montaña blanca o El desvanecimiento entre otras novelas. Toda su obra tiene como finalidad que

el silencio de los humillados y vencidos no triunfe, la palabra ha de hacerse con un espacio en forma de relato. Una historia. ${ }^{53}$

Glosa a Levi, siente la necesidad de traer al presente, de hacer visibles a los desaparecidos, a los Muselmänner, lo relata así:

Sabía cómo escribir el libro que había tenido que abandonar hace quince años antes. Mejor dicho: sabía que podía escribirlo: me había faltado valor para hacerlo. Valor para afrontar la muerte a través de la escritura. Pero ya no tenía necesidad de este valor. ${ }^{54}$

Había desaparecido "la nieve de la memoria, la nieve de antaño", ahora podía devolverles su palabra y que emergieran de las sombras en el que la historia de los vencedores los había puesto. No hay ningún sentimiento de culpabilidad por haber

\footnotetext{
52 Semprún (1998), pp. 172, 181 y 227.

53 Semprún (2001).

54 Semprún (1998), p. 260.
} 
sido un superviviente, nunca lo comprendió, no podía experimentar amargura por lo que había vivido. Vive el desasosiego y la incertidumbre de la vuelta a España en 1953, ante la que había sido su casa

Jamás, en todos esos años vividos en el extranjero, había tenido una sensación tan desgarradora de exilio, de extrañamiento como en aquel momento privilegiado del regreso al paisaje originario. 55

Constata que sus raíces "siempre estarían en ninguna parte, o en cualquiera: en el desarraigo en todo caso". Semprún hace del exilio una patria en que el lenguaje materno ha sido sepultado. La escritura y la dicha que proporciona no pueden apartar y borrar una memoria como la suya, memoria de lo finito. Reconstruye hacia atrás en una "espiral verbal" donde la muerte siempre está ahí, la frase de Wittgenstein: "La muerte no es un acontecimiento de la vida. La muerte no puede ser vivida" aparece una y otra vez en el relato, así como el "No se puede vivir sin la muerte" de estirpe heideggeriana.

La escritura no le apaciguaba, pero "me sumergía en ella". Es la idea de solidaridad, la de su propia historia al llegar al Lager, la de aquel que le puso como profesión "Estucador" y no "Estudiante de filosofía", así le salvó la vida un desconocido. ¿Por qué? Por una idea generosa de lo que es el hombre y la ayuda entre los que estaban allí, Semprún añade el internacionalismo y el que ese hombre era comunista. Destaca el sentimiento de fraternidad y solidaridad con los otros que él experimentó con aquellos que le salvaron la vida. Esas ideas son las grandes esperanzas. La de una fraternidad que dignamente se opone al Mal absoluto, humanidad, libertad, tolerancia, dignidad, solidaridad, esas son las ideas por las que luchar, resistir y vivir.

Tampoco le preocupa el silencio de Dios, sí le preocupa el de los hombres y la impotencia frente al mal: "El nazismo. Mal absoluto. Demasiado largo, demasiado temeroso silencio de los hombres", ahí radica su caracterización del mal absoluto (Das radikal Böse) es el ser humano el que ha de enfrentarse junto a los otros, pues el mal es humano no inhumano. Son los hombres de las SS los que encarnan la maldad y perversidad, la tortura y el horror, hombres cultos que leen a Heine y escuchan - entre las sesiones de cámara de gas - los cuartetos de Schubert y Beethoven para relajarse y descansar. El nazismo creó unas condiciones de vida donde toda perversión era "normal", es el que convierte al mal que perpetra en banal, entre otras cosas porque es ejercido por gente normal que lo que hacían era 'cumplir su deber' como Eichmann.

\footnotetext{
55 Semprún (1998), p. 167.
} 
Un año en Buchenwald me enseñó que el Mal no es lo inhumano, sino, más bien al contrario, una expresión radical de la humana libertad. ${ }^{56}$

Para narrar las geografías y nuevos territorios donde el mal se manifiesta "necesitaríamos un Dostoievski", no obstante afirma en su vuelta a Buchenwald: "Europa empieza a construirse en este lugar".

Paul Steinberg, en Croniques d'ailleurs (1996), literalmente "Crónicas de aquello o de aquél lugar", traducida al castellano como Crónicas del mundo oscuro, es el Henry que describe Primo Lévi en Si esto es un hombre, donde lo relata como "un joven sin compasión" y que "tiene una teoría orgánica y completa sobre las formas de sobrevivir". Su perfil es el de un joven de 17 años que ha vivido en cuatro países, domina cuatro idiomas y no tiene vínculos familiares, eso "eran ventajas para afrontar el cautiverio." Cada día la vida está en juego, no le tienta el escapar, el fugarse, quiere agotar el curso de su vida. No hay ideas religiosas que sustenten esa actitud, solo cabe resistir. Steinberg no sabe nada de la religión judía a pesar de ser judío, en el reconocimiento médico a su llegada al campo causa extrañeza pues no está circuncidado; es igual no hay razón en la vida cotidiana. Él mismo plantea como el término <muerte> no describe lo vivido en el Lager, y manifiesta que habría que inventar otra palabra para describir la

Descomposición, putrescencia, ¿qué término describe la aniquilación física, psíquica y moral, vivida con frecuencia en la ignominia?57

Le inquieta que otros testimonios literarios interfieran en su relato, muy tardío, escrito en 1996, apremiado por estar enfermo de cáncer, evita conscientemente lo que denomina "el museo de los horrores, la letanía de las atrocidades". Su intención la encontramos de un modo diáfano: Dar cuenta de la angustia, recorrer la degradación de los seres humanos, todo esto teniendo la muerte del hombre, entendida como la muerte de los sentimientos y del pensamiento. Ese es el deber del Paul Steinberg que no se recrea en las enfermedades padecidas (erisipela, disentería, hepatitis, úlceras, etc.). Su lógica, como destacó Levi, es la de un "ser frío y calculador", la del superviviente nato, consciente de que en el campo rige una ética distinta que en la vida normal; se siente agradecido a los médicos que lo salvaron, consciente de que para que él se salvara otros murieron. Pero eso forma parte de la lógica en ese momento, cincuenta años más tarde reflexionará sobre ello, pero en aquel tiempo era ajeno a consideraciones de tipo moral.

Comparado con Levi tiene pocas similitudes, pues éste lleva el estigma del haberse salvado y que para eso muchos otros tuvieron que morir; son dos persona-

56 Semprún (2001).

57 Steinberg (2004), p. 45. 
lidades muy diferentes, Steinberg tiene más cosas en común con Améry o Semprún, que con el autor de La llave estrella. Nos relata que la cuestión que se plantea al llegar al campo es: ¿cómo mantenerse vivo en un campo de exterminio? Posteriormente pensará acerca de si es posible conservar una actitud ética ante la muerte, la tortura y el horror. Cumple con algunos requisitos ya dichos: habla alemán e inglés, pero no pertenece a los rebeldes que son víctimas inmediatas, o a los sentimentales que son consumidos "por la angustia, no resistían", ni a los desesperados, no hay héroes, hay que dormir, comer y no tener malas condiciones de trabajo en esa existencia de la indignidad que implica no tener sentimientos ni amistad, un proceso creciente de deshumanización, lo resume en una frase brutal:

Yo, por mi parte, hacía tiempo que había resuelto el problema de la dignidad, que mató a tantos. 58

Es en su vida donde encontramos esa formación para poder afrontar las penalidades y miserias del Lager, en su infancia encuentra una preparación intensiva y completa para el campo; madre muerta al nacer él, hasta los quince años cumplidos no supo que la madrastra, a la que odiaba, no era su madre; ni familia, ni padre, ni hermana, "nada de caricias ni de felicidad", y una capacidad inmensa de "desprecio a la humillación y a los que la proferían". Ese desapego le acompañará siempre, no el "odio que es cálido, pasional; el desprecio, polar." Sorprende cuando resalta su desdén y displicencia a los demás y así mismo, es la lucha por su vida, no hay fuerzas para hacerlo por el otro, no cabe esta posibilidad. Steinberg es una muestra del superviviente, del hombre de los campos, no es el homo sapiens, ni el faber, no. Es más el homo patiens de Viktor Frankl que el homo sacer 59 del que más tarde habló Agamben, ese "hombre carne", que no tiene derecho a vivir y que aquél que lo mate estará libre de cualquier tipo de castigo; es un hombre reducido a no ser ni poder ser nada, pues "éramos las bestias que habían hecho de nosotros"; la pregunta retorna: ¿Sé es culpable por sobrevivir? No hay ningún atisbo de mala conciencia, eso sí, proclama su "rencor eterno" hacia los verdugos y le preocupa

\footnotetext{
58 Steinberg (2004), p. 134.

59 Homo sacer (del latín, "el hombre sagrado" o "el hombre maldito") es una figura del derecho romano: una persona que está prohibida, puede morir por nadie, pero no puede ser sacrificado en un ritual religioso. En el antiguo derecho romano la figura del homo sacer, criatura desprovista de todo derecho que designaba al hombre cuya vida quedaba separada de la vida del resto de los ciudadanos de la polis. Había sido juzgado por un delito y declarado "hombre sagrado". Pero, paradójicamente, según la primera ley tribunicia, "si alguien matara a aquel que es sagrado por plebiscito, no será considerado homicida". Por tanto, puede asesinarse sin que el asesino pueda ser juzgado ya que la misma ley crea las condiciones de su exculpación. Resumiendo, Homo Sacer significa literalmente "hombre carne", al que cualquiera podía exterminar sin incurrir en un delito.
} 
Hacer comprensible aquel mundo, reconstruirlo, es la dificultad a la que nos enfrentamos todos, P. Levi, Frances, Semprún y los demás (...) para ello hay que "navegar entre islotes emergentes de memoria". 60

El símbolo del odio es Rakasch, el Hauptscharführer, personaje perverso que

No inspira un miedo simple, elemental. Hace reinar un horror metafísico (...) El horror convertido en rutina. 61

Es significativo que en ese paralelismo permanente con Levi y el cuestionarse por qué éste puso fin a su vida, Steinberg da la palabra a Kahn, traductor al alemán del autor italiano, quien le recomienda que hable con sus hijos, mujer, con quien sea, pero hable siempre que pueda, "que evite a toda costa encerrarme en mi concha. Según él, Primo Levi murió por "no tener ninguna puerta de salida ni oídos complacientes."62

Jean Améry, (Hans Maier, Viena 1912), va a ser nuestro tercer hombre en este viaje por "los hermeneutas de la noche" que llama Forster63, una narrativa de la muerte y el horror humano, para destacar esas categorías existenciales que conformaban su día a día. Aunque judío, es ajeno a la tradición religiosa y se enterará de lo que es yiddish a los diecinueve años, no hay en su testimonio el sentido religioso que el judaísmo da al Holocausto. Lo que le lleva a escribir es el exterminio de seres humanos sea cual sea su credo, etnia o ideología, de ahí el título de su obra: Más allá de la culpa y la expiación. Tentativas de superación de una víctima de la violencia ${ }^{64}$, incluso pensó en titularlo "Resentimiento", ese rencor reactivo que también ayuda a poder ir tirando, que da energías por la humillación y vejación sufrida. No nos cuenta sus penurias en el campo, hace un ejercicio de fenomenología de su experiencia, de lo que él llama "experiencia subjetiva de la víctima."

Su personaje vive un "desarraigo sin patria", pues la pérdida de la patria es la primera percepción de ese modo de estar en el mundo y en el que uno siente la necesidad de ser otro, de cambiar de nombre (que no de identidad) para sepultar un pasado que es incorporado a ese nuevo yo. A esa pérdida seguirán otras: nación, dignidad, se prescribe de golpe el derecho a la vida e incluso, último refugio, debe ser abandonada. Al igual que sus compañeros que han descrito ese archipiélago del infierno que son los campos, experimenta con la supervivencia tras la liberación de Auschwitz un sentimiento de culpa. La visión de los Muselmänner conllevan la destrucción de ese sujeto, desarrolla una fenomenología existencial del yo donde incor-

\footnotetext{
60 Steinberg (2004), pp. 27 y 29.

61 Steinberg (2004), p. 136 y 143.

62 Steinberg (2004), p. 152.

${ }^{63}$ Forster (2009).

64 Améry (2001).
} 
pora las torturas que sufrió (Semprún jamás pudo narrarlas) y donde no hay justificación posible para el exterminio, ni siquiera para aquellos que se inmolaban y morían en un holocausto purificador, como indica Ocaña:

Su renuencia a toda teleología de la historia de carácter religioso o secular que pretenda dotar de sentido al mal padecido en los campos de concentración mediante compensaciones trascendentes o inmanentes. 65

Améry nos alerta contra una visión o praxis de entender la muerte y el sufrimiento en un sentido religioso, en consecuencia no hay ni existe justificación para ese dolor infligido a las víctimas y que sólo aspira a lograr un mayor sufrimiento en los que la padecen. Para los verdugos no debe haber ni perdón ni olvido y el superviviente jamás podrá superar lo que es injustificable (de ahí que llame a Levi "perdonador"). Améry, vencido, derrotado, al igual que sus compañeros de los Lager estará veinte años sin publicar, dos intentos de suicidio quedan atrás, hasta el último en 1978 en Salzburgo. Los problemas acerca de su propia identidad y la experiencia vivida le llevaron a ello, no supo o no pudo gestionar - como él afirma de Canetti "un compañero de infortunio que, sin duda, ha dominado (gemeistert) mejor todo el pasado que yo"-, esa condición e identidad de víctima de la barbarie nazi. El subtítulo de su libro es ilustrativo de ello, "la tentativa de superación de una víctima de la violencia", él mismo confiesa: "Quien ha sufrido la tortura, ya no puede sentir el mundo como su hogar". Algo más que desconfianza en el mundo y en el hombre. Es herida no cicatrizada, el resentimiento, el rencor de Amery como aquello a lo que también se ha aferrado para poder vivir, recordar, narrar y no olvidar.

\section{Nuestra tarea}

Hemos visto los vericuetos y meandros de la evocación, toda una fenomenología de la recordación donde asistimos a vivencias comunes de exiliados y víctimas sean del país que sea en esta sangrienta y cainita segunda mitad del siglo veinte. Y en el que hemos entrado no va a la zaga, los testimonios de aquellos que han sufrido el mal en primera persona tienen un mismo propósito: la emergencia de esa memoria vencida, sometida y doblegada sea cual sea el espacio y cartografía en que se manifieste.

He intentado que esta memoria humillada aflore por ser un acto de justicia y porque hay un derecho a la memoria, además de ser un deber, más allá de la retórica y de las conmemoraciones o intereses políticos circunstanciales y efímeros. Puede parecer que nuestra perspectiva sea otra, pero en realidad ese pasado insatis-

65 Ocaña (2001), p. 29. 
fecho forma parte de la racionalidad moderna y de su tradición; por tanto no puede quedar al margen de ésta, de ahí que tiene y debe ser incorporada, pues es plural y afecta a muchos, yendo más allá de la mera reparación historiográfica. Hay que poner en primer plano las zonas invisibles, las zonas grises y opacas de nuestro pasado común.

La memoria es un rescate, político y epistemológico, que no puede ser sustraído en tanto que reflexión crítica del mundo en que vivimos. Esa memoria es clave para entender muchos de los acontecimientos de nuestro tiempo: exilios, barbarie, migraciones que son clave para la gestación de nuestro pensamiento. Por eso, es menester, traer a nuestro presente autores olvidados, propuestas arrinconadas con el argumento de que están superadas o de que no sirven para solventar los problemas a que esta crisis sistémica nos ha llevado. Vuelven a oírse viejos slogans nacionalistas, estereotipos del Norte y del Sur, conflictos étnicos como el de la guerra de los Balcanes ha hecho que el genocidio esté muy próximo a nosotros... con nula reacción, no se ha superado nada y los viejos fantasmas vuelven. Al menos ya nadie osa hablar de tiempos de progreso, éste se ha convertido en un salvaje desarrollo que hace del hombre un consumidor satisfecho y la humanidad se siente cada más reducida.

La racionalidad moderna se ha construido de muchos modos y si algo hay que conocer a fondo de ella son sus patologías, únicamente así podremos afrontar sus efectos. No hay otro modo de construir nuestro futuro y vivir nuestro presente que incorporar y rescatar definitivamente todas esas tradiciones con sus horrores, verdugos, humillados, vencidos, desaparecidos, etc. Para que dejen de estar alojados en la memoria histórica y formen parte de una memoria colectiva, con sus luces y sombras, pero común a nuestra historia, para que podamos convivir sin odio.

\section{Referencias bibliográficas}

AmÉRY, J. (2001): Más allá de la culpa y la expiación. Tentativas de superación de una víctima de la violencia, Valencia, Pre-Textos.

Arenas, H. J. (2008): Entrevista a Reyes Mate, en Rebelión. Revista electrónica, 18 septiembre de 2008. http://www.rebelion.org/

Benjamin, W. (1990): Discursos Interrumpidos, I, trad. Jesús Aguirre, Madrid, Taurus.

Benjamin, W. (1991): "El narrador", en Para una crítica de la violencia y otros ensayos. Iluminaciones $I V$, Madrid, Taurus.

Cohen, E. (2006): Los narradores de Auschwitz, México, Fineo.

Forster, R. (2009): Los hermeneutas de la noche. De Walter Benjamin a Paul Celan, Madrid, Trotta.

Kerstestz, I. (2001): Sin destino, Barcelona, Acantilado. 
Klemperer, V. (2001): LTI. La lengua del Tercer Reich. Apuntes de un filólogo, Barcelona, Minúscula.

Levi, P. (1989): Los hundidos y los salvados, Barcelona, Muchnik..

LEVI, P. (1997): La tregua, Barcelona, Muchnik.

LeVI, P. (1998): Si esto es un hombre, Barcelona, Muchnik.

Levi, P. (2005): Regreso a Auschwitz, entrevista inédita transcrita por Marco Belpoliti, trad. Ana Nuño, Letras Libres $n^{\circ} 48$, septiembre.

MATE R. (1991): La razón de los vencidos, Barcelona, Anthropos.

Mate, R., (2003): Memoria de Auschwitz, Madrid, Trotta.

Mate, R. (2006): Medianoche en la historia, Madrid, Trotta.

MATE, R. (2008): La herencia del olvido. Ensayos en torno a la razón compasiva, Madrid, Errata Naturae.

Mate, R. (2011): Tratado de la injusticia, Barcelona. Anthropos.

Novella, J. (2008): "El silencio de la memoria (del exilio y el pensamiento español)", en Sánchez Cuervo, A., (coord.), Las huellas del exilio. Expresiones culturales de la España peregrina, Madrid, Tébar; (2012): "Historia de las ideas, pensamiento y exilio" en Ensayos sobre Historia del Pensamiento Español. Homenaje a José Luis Abellán, Rivera García, A. y Villacañas J. L., (eds.), Murcia, Editum.

OCAÑA, E. (2001): "La herida de Améry: Más allá de la mentalidad expiatoria" en Améry (2001).

Ricoeur, P. (2003): La memoria, la historia, el olvido, trad. de A. Neira, Madrid, Trotta.

SEMPrún, J. (1963,1976 ed. esp.): El largo viaje, Barcelona, Seix Barral.

SEMPRún, J. (1998): La escritura o la vida, Barcelona, Tusquets.

SEMPrún, J. (2001): Entrevista a Jorge Semprún en El País 19 de mayo de 2001.

Steinberg, P. (2004): Crónicas del mundo oscuro, Barcelona, Círculo de Lectores.

Traverso, E. (2001): La historia desgarrada. Ensayo sobre Auschwitz y los intelectuales, Barcelona, Herder.

Traverso, E. (2007): "La memoria de la Shoah como religión civil", en El pasado, instrucciones de uso. Historia, memoria y politica, Madrid, Marcial Pons.

Zambrano, M. (1973): El hombre y lo divino, México, Breviarios FCE.

ZERTAL, I. (2010): La nación y la muerte. La Shoá en el discurso y la política de Israel, Madrid, Gredos.

Jorge Novella Suarez

Facultad de Filosofía

Universidad de Murcia

jnovella@um.es 